\title{
Sistem Keamanan Pada Ruangan Server Menggunakan Teknologi Berbasis Internet of Things dan Aplikasi Blynk
}

\author{
Sufian ${ }^{1}$, Didik Setiyadi ${ }^{2}$ \\ 1 Teknik Informatika; Universitas Bina Insani; Jl. Siliwangi No.6 Rawa Panjang Bekasi Bekasi \\ Timur 17114 Indonesia;Telp. (021) 82436 886, Fax. (021) 824009 24; \\ e-mail: Jrsofyan409@gmail.com \\ ${ }^{2}$ Teknik Informatika; Universitas Bina Insani; Jl. Siliwangi No.6 Rawa Panjang Bekasi Bekasi \\ Timur 17114 Indonesia;Telp. (021) 82436 886, Fax. (021) 824009 24; \\ e-mail: didiksetiyadi@binainsani.ac.id \\ * Korespondensi: e-mail:didiksetiyadi@binainsani.ac.id
}

Diterima: 30 April 2021; Review: 7 Mei 2021; Disetujui: 15 Mei 2021, 186-195

Cara sitasi: Sufian, Setiyadi D. 2020. Sistem keamanan ruanagan ServerInformatics for Educators and Professionals. 5 (2): 186-195

\begin{abstract}
Abstrak: Keamanan salah satu dari kehidupan manusia untuk memberikan kenyamanan dalam melakukan aktivitasnya. sebuah sistem yang akan membantu untuk melakukan pengawasan terhadap lingkungan sekitar yang sebelumnya dalam proses pemantauan dilakukan secara fisik dan mebutuhkan banyak tenaga untuk melakukan pengecekan. Sistem keamanan berbasis teknologi Internet Of things dan aplikasi Blynk sebagai remote kontrol ini dapat membantu dalam proses pengawasan dari kejahatan dan bencana yang nantinya ketika ada sesuatu, misalnya ada yang masuk kedalam ruangan tersebut tanpa sepengetahuan maka teknologi tersebut mengirim notifikasi terhadap pegguna.
\end{abstract}

Kata kunci: Keamanan, Internet of Things, Aplikasi Blynk

Abstract: Security is one of human life to provide comfort in carrying out its activities. a system that will help to supervise the surrounding environment which was previously carried out physically and requires a lot of energy to check. The security system based on Internet of things technology and the remote control application as a remote control can help in the process of monitoring of crimes and disasters which later when something happens, for example someone enters the room without the knowledge, the technology sends a notification to the user.

Keywords: Security, Internet of Things, Blynk Application

\section{Pendahuluan}

Aspek keamanan merupakan bagian dari kenyamanan kehidupan manusia, keamanan bertujuan menciptakan rasa aman dari berbagai jenis tindakan yang tidak diinginkan oleh pemiliknya misalkan dari tindakan kriminalitas atau bencana yang menimbulkan kerugian bagi manusia dan dengan adanya rasa aman manusia akan lebih tenang Dalam melakukan kegiatan sehari-hari, pengawasan suatu objek merupakan suatu pekerjaan yang biasa dilakukan oleh manusia. Pengawasan tersebut dilakukan pada benda yang bergerak ataupun tidak bergerak. Pengawasan tersebut biasanya dilakukan secara manual yang diawasi secara langsung atau berada didekat objek. Hal ini menyebabkan membuang banyak tenaga dan waktu manusia. Dengan demikian, perlu memanfaatkan teknologi untuk menggantikan pemantauan secara manual, salah satunya yaitu memanfaatkan sebuah teknologi. 
Teknologi berbasis Internet Of things (IoT) merupakan teknologi yang dapat membantu manusia untuk melakukan aktivitasnya. loT menyambungkan antara alat-alat elektronik semisal lampu, bahkan pintu rumah yang terkoneksi ke Internet yang dapat dipantau dan dikendalikan dari jarak jauh melalui smartphone yang digunakan.

Dari penjelasan yang sudah dijabarkan sebagaimana di latar belakang, terdapat beberapa identifikasi masalah yang timbul, yaitu: (1). Dalam melakukan pengawasan masih dilakakukan secara manual atau pengawasansecara langsung. (2). Belum adanya alat untuk membantu melakukan pemantauan dan pengendalian dari jarak jauh. (3) Belum adanya alat bantu untuk meminimalisir terjadinya tindakan kriminal dan bencana.

Maka dalam membuat sistem keamanan ruangan ini memiliki tujuan dan manfaat, berikut tujuan dari dari pembuatan sistem keamanan (1). Membangun prototype sistem keamanan ruangan Server menggunakan teknologi Internet Of things. (2). Membuat prototype sistem keamanan ruangan Server menggunakan teknologi Internet Of things agar dapat melakukan pengawasan serta dikendalikan melalui smartphone. (3). Membuat prototype sistem keamanan ruangan Server menggunakan teknologi Internet Of things untuk meminimalisir terjadinya bencana ataupun tindakan kejahatan. Adapun manfaat dari penelitian ini sebagai berikut: (1). Memudahkan dalam mengimpletasikan hasil dari rancangan sistem keamanan ruangan dalam bentuk Prototype menjadi sebuah pertimbangan bagi seseorang dalam melakukan pengawasan dan pengendalian yang tidak dilakukan secara langsung pada ruangan tersebut. (2). Dengan adanya sistem keamanan ini dapat membantu seorang dalam melakukan pengawasan dan pengendalian secara efisien.

[1]. Internet Of things (IOT) sebuah akses perangkat elektronik melalui media internet. akses sebuah perangkat tersebut karena melibatkan antara manusia dengan perangkat ataupun bisa melibatkan perangkat dengan perangkat dengan memanfaatkan jaringan internet. Akses perangakat tersebut dapat membagi data, akses dan juga untuk mempertimbangkan dalam aksesnya. Internet Of things (iot) biasnya dimanfaatkan sebagai media yang dapat membantu selayaknya menggantikan manusia dalam melakukan pengawasan di dunia industri dan beberapa tempat yang sangat luas dan beragam (contoh bidang lingkungan, kawasan rumah sakit, di kawasan umum, sektor keamanan dan sektor transportasi). Internet Of things (IoT) dapat dikembangkan dengan media perangkat elektronika yang umum seperti Arduino untuk keperluan yang spesifik (khusus). loT juga dapat dikembangkan aplikasi terpadu dengan sistem operasi android.

[2] Arduino adalah suatu open-source platform elektronic yang berbasis kemudahan penggunaan (easy to use) baik hardware maupun software. Arduino uno Merupakan alat yang dapat memproses hasil dari inputan dari komponen alat lainnya dan apikasi Blynk sebagai user interface. Pada sistem keamanan ruangan Server Terdapat beberapa alat yang dibutuhkan. Sensor dalam sistem keamanan yaitu(Flame sensor, sensor Ultrasonic dan sensor MQ-2). [3]. Flame sensor ini dapat mendeteksi nayala api dengan panjang gelombang 760nm- $110 \mathrm{~nm}$. Sennsor ini dapat sangat berguna yang dapat dijadikan mata bagi robot untuk dapat mendeteksi sumber nyala atau mencari bola. [4]. HC-SR04 memiliki 2 komponen diantaranya ultrasonic receiver dan ultrasonic transmitter. Fungsi dari keduan komponen tersebut ultrasonic receiver menangkap hasil pantulan gelombang sedangkan ultrasonic transmiter dapat memancarkan gelombang. [5]. Sensor MQ-2 atau sensor asap dapat mendeteksi kebocoran pada gas LPG, i-butana, propana, metana, alkohol, hidrogen dan asap. Inti daripada $M Q-2$ adalah material yang bersifat sensitif, karena kesensitipannya yang tinggi dan waktu respon yang cepat terhadap konsentrasi gas. Terdapat akuator sebagi alat untuk melakukan hal yang diperlukan. [4][4]. Buzzer merupakan sebuah komponen elektronika yang masuk dalam keluarga transduser, yang dimana dapat mengubah sinyal listrik menjadi getaran suara. [5]. Pompa Air merupakan sebuah alat yang digunakan untuk Memindahkan cairan / air dari satu tempat ke tempat lain yang biasanya menggunakan energi listrik sebagai tenaga untuk mendorng air. [6]. Modul yang berfungsi sebagai peranti Wi-Fi, yang dibuat oleh perusahaan China bernama Espressif. Salah satu jenisnya adalah ESP-01. Dengan menggunakan peranti ini. Arduino dapat berhubungan dengan Internet sehingga Arduino dapat digunakan untuk mengirimkan data yang berasal dari sensor ke database server. 


\section{Metode Penelitian}

Teknik Pengumpulan data, Dalam melakukan suatu penelitian. [7]. usaha yang sadar untuk mengumpulkan informasi yang dirangkul sengaja dengan metode normalisasi. Dengan prosedur yang terstandar. Observasi adalah teknik pengumpulan data dengan dilakukan pengamatan terhadap obyek. Teknik Observasi dilakukan guna mengumpulkan data secara sistematis melalui pengamatan dan pencatatan terhadap fenomena yang diteliti yang berkaitan dengan keamanan. Dengan melakukan penelitian dan pengamatan secara langsung terhadap obyek penelitian. Studi pustaka dilakukan dalam keseluruhan proses penelitian sejak awal hingga sampai akhir penelitian, dengan melakukan aktivitas pencarian data dan informasi berupa teori melalui buku-buku, jurnal, sumber bacaan elektronik, memanfaatkan berbagai macam pustaka yang berkaitan dengan penelitian yang tengah dipahami untuk memperoleh data. [8]. Studi pustaka atau literature review Penting untuk makalah logis sebagai percakapan penelitian masa lalu dan referensi logis yang diidentifikasi dengan eksplorasi yang digambarkan oleh pencipta di makalah.

[9]. Evolutionary Prototype adalah model pengembang interne of things yang meliputi (Analisis Kebutuhan User, Membuat Prototype, Menyesuaikan Prototype Dengan keininan User Dan Menggunakan Prototype). Sumber:

Berikut adalah kerangka pemikiran yang merupakan langkah-langkah dalam pembuatan sistem keamanan ruangan Server

Sumber : (Hasil Penelitian 2021)

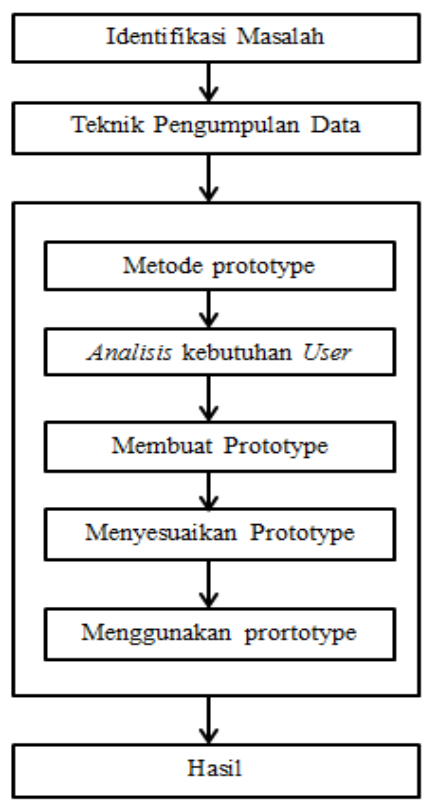

Gambar 1. Kerangka Pemikiran

Berdasarkan kerangka pemikiran yang sudah dibuat diatas maka penulisan akan menguraikan masing-masing tahap sebagai berikut. (1). Identifikasi Masalah. Dalam tahapan ini melakukan analisa kebutuhan yang ada pada ruangan tersebut sehingga menemukan masalah atau kekukarangan yang menjadi ancaman yang tidak diinginkan oleh pemiliknya. Dengan menemukan masalah atau kekurangan memudahkan untuk melakukan pekerjaan ketahap selanjutnya. (2).Teknik Pengumpulan data. Melakukan penelitian secara langsung guna mendapatkan informasi mengenai permasalahan yang terdapat pada ruangan Server, dan melakukan diskusi dengan yang bertanggung jawab untuk menemukan jalan keluar keluarnya. (3). Analisa kebutuhan user. Melakukan penelitian terhadap ruangan server guna mendapatkan informasi khusunya dari segi keamanannya. Dan pada saat proses penganalisan peneliti mengetahui kurangnya rasa terhadap ruangan Server ketika tidak ada pengawasan secara langsung. Solusi yang tepat untuk melakukan pemantauan terhadap rungan Server yaitu dengan cara menerapkan sistem keamanan ruangan dimana dalam sistem keamanan tersebut 
terdapat sensor Ultrasonic yang terhubung ke alarm, sensor pendeteksi kebakaran (Flame sensor), sensor pendeteksi kebocoran gas (MQ-2) dan aplikasi Blynk sebagai user interface. (4). Membuat prototype. Pada tahapan ini melakukan perangkaian terhadap sistem yang dibutuhkan pada sistem keamanan ruangan Server Pada tahap ini melakukan rangkaian keamanan ruangan server, rangkaian user interface dan rangkaian sistem berjalan. (5). Menyesuaikan prototype. Pada tahapan ini berfokus untuk melakukan rancangan terhadap sistem keamanan ruangan Server dan perancangan terhadap user interface. Agar saling berhubungan antara hardware dan software Dan melakukan pengujian terhadap sistem keamanan. (6). Menggunakan prototype. Pada tahapan ini mengimplementasikan hasil dari rancangan sistem keamanan Server baik dari perangkat keras maupun perangkat lunak. (7). Hasil. Dalam tahapan Ini mampu menghasilkan suatu sistem yang sesuai dengan kebutuhan pengguna. Yang dimana dalam sistem tersebut keamanan terhadap pintu ruangan yang sudah ditanam menggunakan sensor Ultrasonic yang terhubung dengan Buzzer, mendeteksi terjadinya kebakaran, mendeteksi terjadi kebocoran gas serta pengguna bisa mendapatkan informasi mengenai kondisi pada ruangannya.

\section{Hasil dan Pembahasan}

Analisa kebutuhan User. Analisa kebutuhan user merupakan tahapan menganalisa yang diperlukan dalam membangun sebuah sistem keamanan ruangan, dalam penganalisaan ini ditemukan permasalahan terhadap ruangan. diharapkan pengembang bisa mengurangi kelemahan terhadap ruangan tersebut, diperlukan beberapa software dan komponen perangkat lunak dalam pembuatan sistem keamanan.

Kebutuhan Pengguna. Berikut tabel kebutuhan pengguna dalam melakukan pengawasan serta alat bantu yang dapat mengontrol terhadap sistem keamanan ruangan.

Tabel1. Tabel kebutuhan Pengguna

\begin{tabular}{ccc}
\hline No & Keterangan & Deskripsi \\
\hline 1 & Aplikasi Blynk & Untuk memantau dan melakukan pengontrolan terhadap sistem \\
keamanan
\end{tabular}

Sumber : (Hasil Penelitian 2021)

Tabel dibawah merupakan perangkat lunak yang digunakan untuk melakukan pembuatan sistem dan penggunaan perangkat untuk menggunakan sistem keamanan ruangan, berikut tabel kebutuhan perangkat lunak yang dibutuhkan.

Tabel.2. Tabel Perangkat untuk membantu penggunaan sistem keamanaan

\begin{tabular}{ccc}
\hline No & Software & Fungsi \\
\hline 1 & Windows & sebagai server local \\
\hline 2 & Android & $\begin{array}{c}\text { sebagai oprating sistem pada user } \\
\text { interface }\end{array}$ \\
\hline 3 & Blynk Aplication & $\begin{array}{c}\text { sebagai user interface sistem keamanan } \\
\text { ruangan }\end{array}$ \\
\hline
\end{tabular}

Sumber : (Hasil Penelitian 2021)

Tabel 3. Perangkat lunak dalam pembuatan sistem keamanan

\begin{tabular}{cccc}
\hline No & Software & Spesifikasi & Fungsi \\
\hline 1 & Windows & Windows 7,9,10 & $\begin{array}{c}\text { Sebagai oprating sistem dalam } \\
\text { pembuatan sistem }\end{array}$ \\
\hline 2 & Fritzing & fritzing0.9.3b.32 & Untuk merangkai komponen alat sistem \\
\hline 3 & Arduino IDE & 1.8 .13 & $\begin{array}{c}\text { Untuk menulis sour code yang akan di } \\
\text { tanam pada aruduino }\end{array}$ \\
\hline 4 & Star Uml & 4.0 .0 & $\begin{array}{c}\text { Untuk membuat flowcart, use case, } \\
\text { diagram Activity, squance diagram dan } \\
\text { class diagram }\end{array}$ \\
\hline 5 & Blynk server & 0.41 .16 & $\begin{array}{c}\text { Digunakan sebagai server local pada } \\
\text { sistem keamanan pada ruangan Server }\end{array}$ \\
\hline sil Penelitian 2021) & &
\end{tabular}


Tabel 4. Kebutuhan perangkat keras pada sistem keamanan ruangan

\begin{tabular}{|c|c|c|c|c|}
\hline No & $\begin{array}{l}\text { Nama } \\
\text { Perangkat }\end{array}$ & Jumlah & Spesifikasi & Fungsi \\
\hline 1 & Arduino UNO & 1 & $\begin{array}{l}\text { Operating Voltage : } 5 \mathrm{~V} \\
\text { Digital I/O Pins : } 14 \\
\text { Analog Input Pins : } 6\end{array}$ & $\begin{array}{l}\text { Sebagai mikrokontroler terhadap } \\
\text { sistem keamanan ruangan }\end{array}$ \\
\hline 2 & Breadboard & 1 & $\begin{array}{l}\text { Breadboard Mini Solderless } \\
1 \text { Terminal Strip Tie-point } 400\end{array}$ & $\begin{array}{l}\text { Sebagai pengbung kabel dari alat } \\
\text { ke alat yang lainnya }\end{array}$ \\
\hline 3 & Kabel jumper & 30 & $\begin{array}{l}\text { Male to Male } \\
\text { Male to Female } \\
\text { Female to Female }\end{array}$ & $\begin{array}{l}\text { Sebagai penghubung dari alat } 1 \\
\text { ke komponen lainnya. }\end{array}$ \\
\hline 4 & $\begin{array}{l}\text { Relay } 1 \\
\text { chanel }\end{array}$ & 1 & $\begin{array}{l}\text { Tegangan Kerja: } 5 \mathrm{~V} D C \\
\text { Jenis Trigger: Low Active }\end{array}$ & Mengontrol pompa air \\
\hline 5 & Adaptor & 1 & $\begin{array}{l}\text { Tegangan input: } 100-240 \text { VAC } \\
\text { Tegangan output: } 9 \mathrm{~V} D C \\
\text { Arus Max.: } 1 \mathrm{~A} / 1000 \mathrm{~mA}\end{array}$ & $\begin{array}{l}\text { Untuk mengalirkan listrik dari } \\
\text { sumber listrik utama }\end{array}$ \\
\hline 6 & Flame sensor & 1 & $\begin{array}{l}\text { Tegangan Operasional : 5V } \\
\text { Jarak Deteksi : } 0 \text { - } 1 \text { meter Output : Digital } \\
\text { Logic /analog }\end{array}$ & Untuk mendeteksi adanya api \\
\hline 7 & Sensor MQ-2 & 1 & $\begin{array}{l}\text { Operating Voltage is }+5 \mathrm{~V} \text {. } \\
\text { Analog output voltage: } \mathrm{V} \text { to } 5 \mathrm{~V} \\
\text { Digital Output Voltage: } 0 \mathrm{~V} \text { or } 5 \mathrm{~V}\end{array}$ & Mendeteksi adanya kbocoran gas \\
\hline 8 & $\begin{array}{l}\text { Sensor } \\
\text { Ultrasonic }\end{array}$ & 1 & $\begin{array}{l}\text { Tegangan : } 5 \mathrm{~V} \text { DC.Arus statis : < } \\
2 \mathrm{~mA} \text {. Level output : } 5 \mathrm{v}-0 \mathrm{~V} \text {. } \\
\text { Jarak yg bisa dideteksi : } 2 \mathrm{~cm}-450 \mathrm{~cm} \\
(4.5 \mathrm{~m}) \text { Tingkat keakuratan : up to } 0.3 \mathrm{~cm} \\
(3 \mathrm{~mm})\end{array}$ & Mendeteksi pintu ruangan terbuka \\
\hline 9 & Pompa air & 1 & $\begin{array}{l}\text { DC } 3-5 \text { volt } \\
\text { Arus } 130-220 \mathrm{~mA} \\
\text { Besar pipa output } 7.5 \mathrm{~mm}\end{array}$ & $\begin{array}{l}\text { Melakukan pemadaman terhadap } \\
\text { api }\end{array}$ \\
\hline 10 & Buzzer & 1 & $\begin{array}{l}\text { Tegangan: 5V } \\
\text { Jenis: Active Buzzer }\end{array}$ & $\begin{array}{l}\text { Sebagai alarm pada sistem } \\
\text { keamanan }\end{array}$ \\
\hline 11 & Esp-8266 & 1 & $\begin{array}{l}\text { Tegangan: } 3.3 \text { VDC. } \\
\text { Terdapat pin RX/TX UART } \\
\text { untuk komunikasi seria }\end{array}$ & $\begin{array}{l}\text { Sebagai penghubung antara } \\
\text { sistem dengan perangkat android }\end{array}$ \\
\hline
\end{tabular}

Sumber : (Hasil Penelitian 2021)

Pembuatan Prototype ini meliputi rangkaian terhadap perangkat yang dibutuhkan pada sistem keamanan ruangan ServerBerikut Rangkaian Sistem Keamanan Ruangan Server.

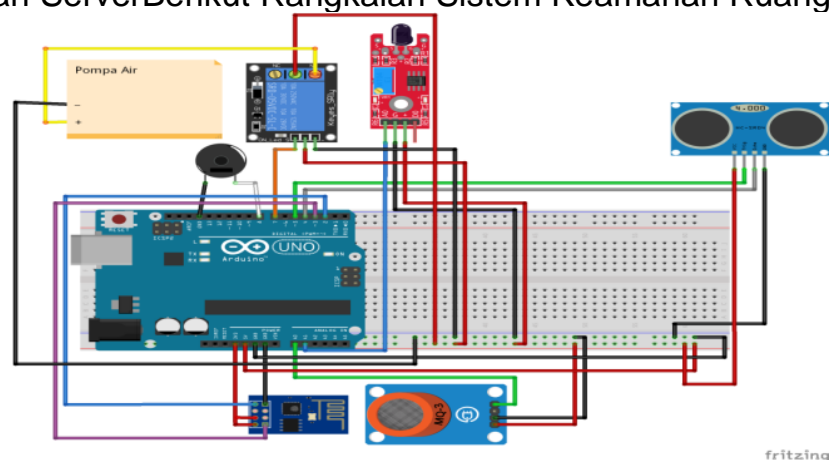

Sumber : (Hasil Penelitian 2021)

Gambar 2. Rangkaian sistem keamanan ruangan Server

Pada pemodelan sistem ini menjelaskan sistem berjalan yang akan dibangun. Pemodelan sistem ini digambarkan dalam bentuk flowchart (diagram alur) yang tersaji pada gambar dibawah ini. 


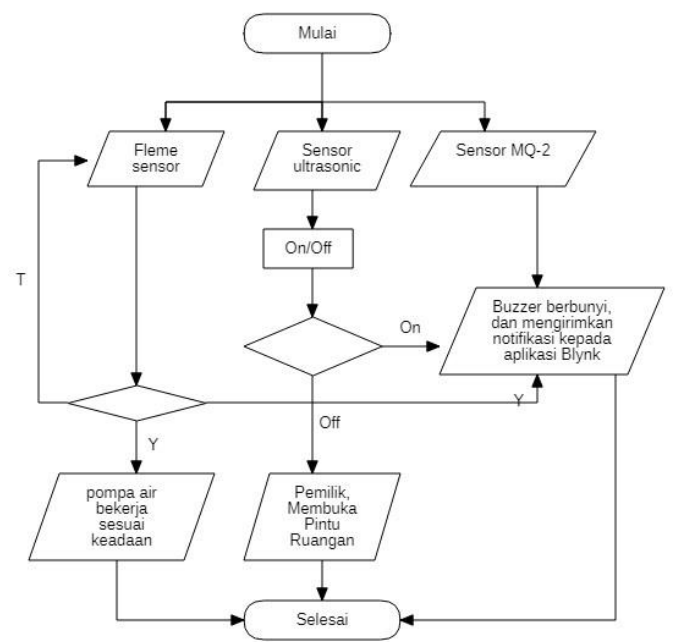

Sumber : (Hasil Penelitian 2021)

Gambar 3. Flowcart perancangan sistem

[10]. Use case diagram menggambarkan fungsionalitas yang diharapkan dari sebuah sistem. Use case Diagram menjelaskan gambaran skenario dari interaksi antara pengguna dengan sistem. Use case diagram menggambarkan hubungan antara aktor dan kegiatan sistem yang berjalan.

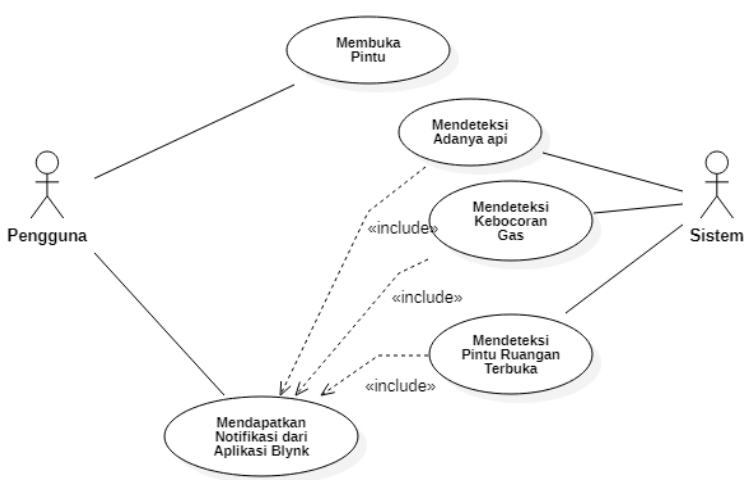

Sumber : (Hasil Penelitian 2021)

Gambar 4. Use case diagram sistem keamanan

Berdasarkan gambar diatas menjelaskan mengenai Pengguna dan sistem. Pengguna melakukan aktivitas berupa membuka pintu dan melihat notifikasi yang dikirim dari perangkat sistem keamanan ke aplikasi Blynk, sedangkan sistem dapat mendeteksi adanya pintu ruangan terbuka tanpa sepengetahuan pengguna, mendeteksi kebocoran gas dan juga dapat medeteksi adanya api.

Pada tahapan Menyesuaikan prototype terdapat rancangan perangkat keras serta user interface Sistem Keamanan. Berikut Rancangan sistem Keseluruhan pada sistem keamanan ruangan Server dalam bentuk prototype. 
Sumber : (Hasil Penelitian 2021)

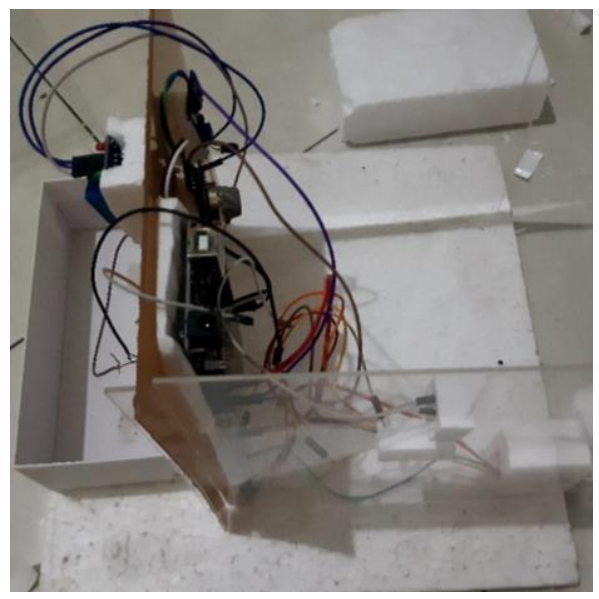

Gambar 5. Rancangan sistem keamanan

Rangkaian Ini membutukan Arduino uno sebagai procesing, Sensor Ultrasonic, Flame sensor dan Sensor MQ-2 sebagai alat yang mendeteksi suatu keadaan yang akan di proses, Buzzer dan Pompa air sebagai Akuator yang dapat melakukan hal yang diperlukan dan module WiFi sebagai Network Conectivity yang bisa menghubungkan perangkat loT dengan Internet atau dengan perangkat lainnya.

Berikut tampilan User interface Sistem keamanan ruangan

Sumber : (Hasil Penelitian 2021)

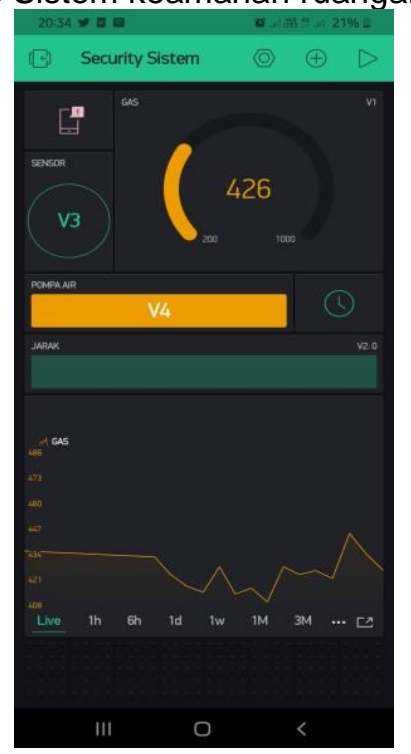

Gambar 6. User interface sistem keamanan

Pada gambar tampilan antar muka diatas (user interface) terdapat widget box notifikasi, Button Sensor On Off (V3) berfungsi On Off sensor Pendeteksi pintu ruangan, GAS (V1) menampilkan Output sensor MQ-2, Button pompa air (V4) On off manual pompa air, jarak (V2) menampilkan output sensor jarak dan super chart untuk menampilkan naik turunnya angka gas.

Melakukan testing terhadap sistem keamanan ruangan, Pada tahapan ini berisi proses pengujian sistem keamanan ruangan Server, setelah di uji coba pengguna akan mendapatkan notifikasi dari aplikasi Blynk apabila keadaan ruangan dalam keadaan kondisi tidak aman seperti, memasuki ruangan tanpa se izin pengguna, adanya api dalam ruangan serta kebocoran gas pada ruangan. Pengujian ini menggunakan konsep pengujian black box sisem, yaitu pengujian dengan mengamati secara fungsi dari perangkat dan notifikasi yang telah dibuat. 
Pengujian Flame sensor, Pengujian ini dilakukan dengan cara menyalakan api pada Flame sensor, dimana ketika mendeteksi api maka Flame sensor akan memberikan inputan sinyal ke Arduino untuk membunyikan Buzzer, memadamkan api dan mengirim notifikasi ke aplikasi Blynk bahwa ada api di dalam ruangan.

Tabel 5. Pengujian Flame sensor

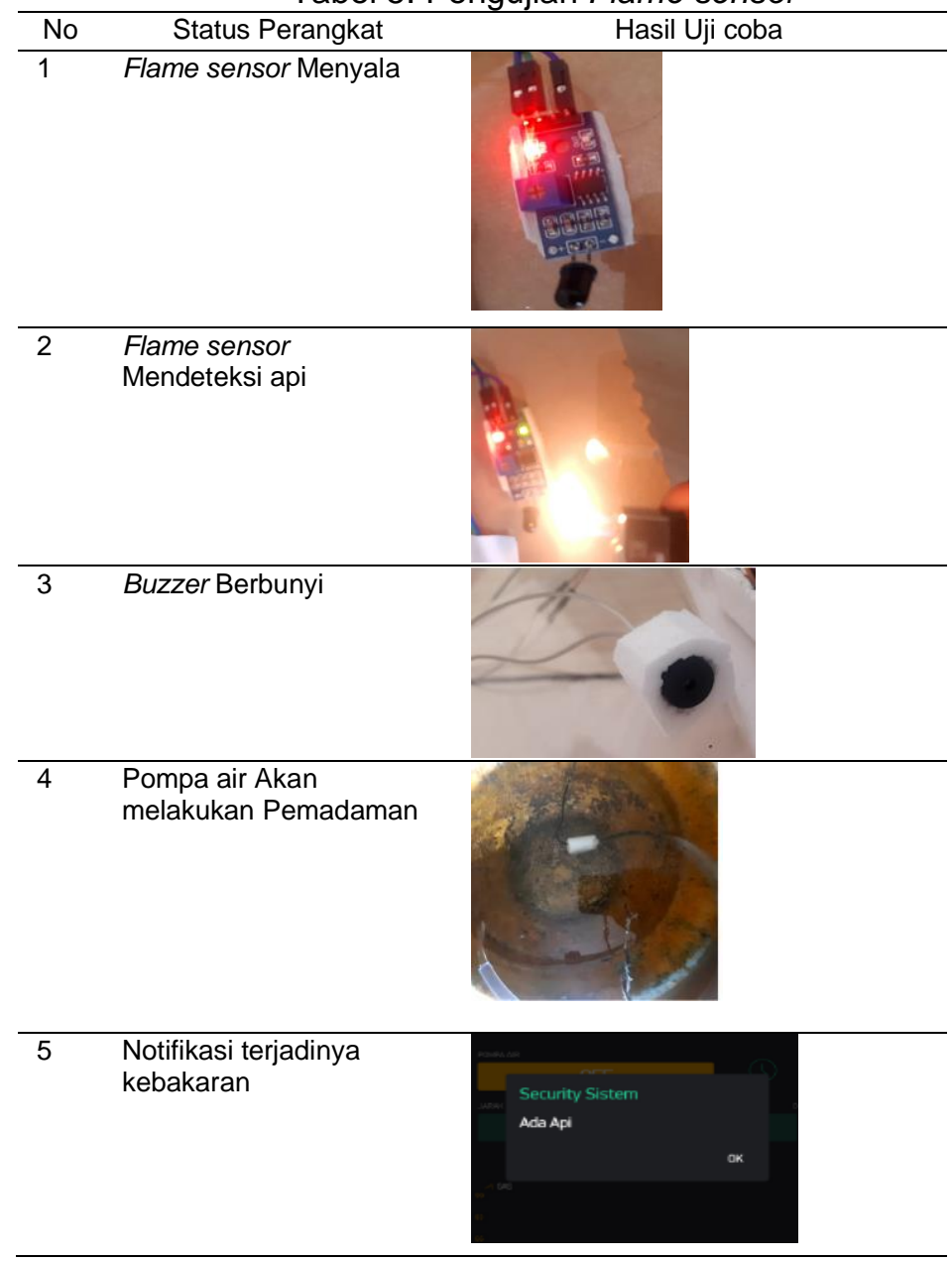

Sumber : (Hasil Penelitian 2021)

Pengujian Sensor MQ-2 Pada tahapan pengujian ini dilakukan dengan cara menyemprotkan gas terhadap sensor $M Q-2$, kemudian apa bila sensor mendeteksi adanya api maka akan mengirim sinyal ke Arduino untuk membunyikan Buzzer dan mengirim nootifikasi ke aplikasi Blynk.

Tabel 6. Pengujian sensor MQ-2

\begin{tabular}{lll}
\hline No & Status Perangkat & Hasil Uji coba \\
\hline 1 & Mendeteksi adanya gas \\
\hline 2 & Buzzer berbunyi
\end{tabular}




\begin{tabular}{|c|c|c|}
\hline No & Status Perangkat & Hasil Uji coba \\
\hline 3 & Notifikasi Adanya gas & 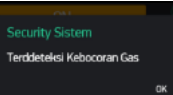 \\
\hline 4 & Ada Kebocoran gas & \\
\hline
\end{tabular}

Sumber : (Hasil Penelitian 2021)

Sensor Ultrasonic,Sensor ini di uji dengan meletekan suatu benda di ujung Sensor Ultrasonic agar mendeteksi pintu ruangan (jarak sensor dengan pintu). Apabila sensor ini mendeteksi pintu ruangan terbuka maka sensor mengirim sinyal ke Arduino untuk membunyikan Buzzer dan mengirim notifikasi ke aplikasi Blynk.

Tabel 7. Pengujian deteksi ruangan

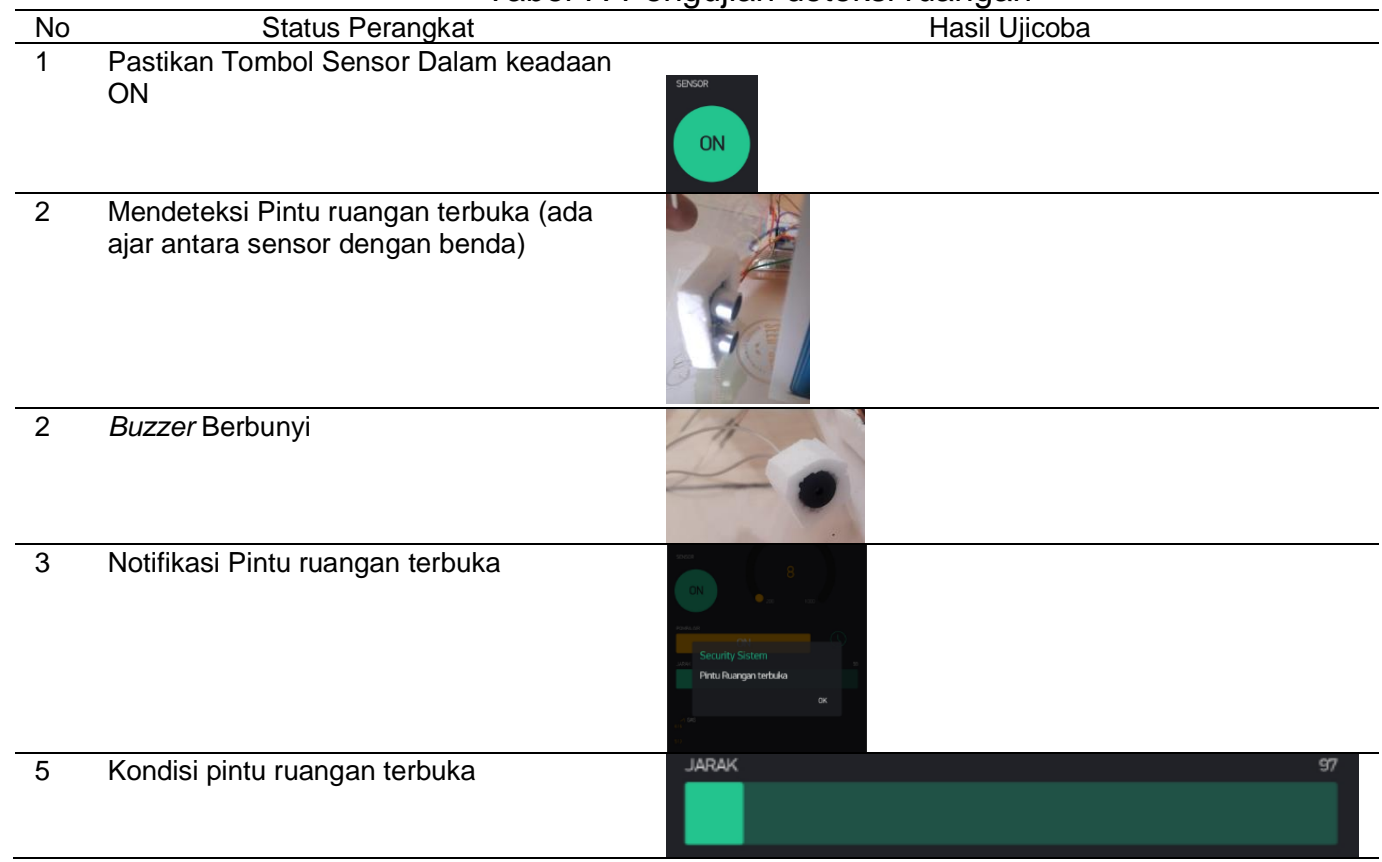

Sumber : (Hasil Penelitian 2021)

Tabel 8. Ruangan Tidak terdeteksi

\begin{tabular}{lll}
\hline No & Status Perangkat \\
\hline 1 & Pastikan Button Sensor dalam keasan Off \\
\hline $2 \quad \begin{array}{l}\text { Pintu dalam Keadaan terbuka sehingga sensor } \\
\text { tidak mendetksinya }\end{array}$
\end{tabular}




\begin{tabular}{lll}
\hline No & \multicolumn{1}{c}{ Status Perangkat } & \\
\hline 3 & $\begin{array}{l}\text { Jarak tidak terdeteksi apabila Button dalam } \\
\text { Keadaan Off }\end{array}$ & \\
& \\
Sumber : (Hasil Penelitian 2021)
\end{tabular}

\section{Kesimpulan}

Berdasarkan hasil penelitian pada pembuatan sistem keamanan pada ruangan Server, maka dihasilkan sebuah alat yang mampu membantu pemilik ruangan dalam melakukan pengawasan terhadap ruangan dari kejahatan maupun bencana. Setelah hasil penelitian tersebut, maka dapat disimpulkan (1). Prototype sistem keamanan ruangan dapat berfungsi dengan baik Sehingga dapat membantu dalam melakukan pengawasan. (2). Prototype Sistem keaamanan ruangan dapat membantu untuk menimalisir terjadi nya bencana kebakaran, karena dalam sistem tersebut terdapat terdapat Flame sensor. (3). Prototype sistem keamanan ruangan dapat membantu dalam mendeteksi terjadinya tindakan kejahatan.

\section{Referensi}

[1] S. Wasista, Setiawardhana, D. ayu Sarawati, and E. Susanto, Aplikasi Internet Of things (iot) dengan Arduino dan Android. Yogyakarta: CV BUDI UTAMA, 2019.

[2] Z. Ahyadi, Belajar Antarmuka Arduino Secara Cepat Dari Contoh. Banjarmasin: POLIBAN PRES, 2018.

[3] Y. Yudhanto and A. Azis, Pengantar Teknologi Internet of Things. Surakarta: UNS Press, 2019.

[4] M. N. Fauzan and L. C. Adiputri, TERUTORIAL MEMBUAT PROTOTIPE PREDIKSI KETINGGIAN AIR (PKA)UNTUK PENDETEKSI BANJIR PERINGATAN DINI BERBASIS IOT. Bandung: Kreatif Industri Nusantara, 2019.

[5] S. M. A. Dwitya P, M. N. Fauzan, and S. F. Pane, TERUTORIAL PEMBUATAN PROTOTYPE PENDETEKSI KEBAKARAN (FIDO) BERBASIS METODE NAIVE BAYES. Bandung: Kreatif Industri Nusantara, 2020.

[6] A. Kadir, Pemrograman Arduino \& Android Menggunakan App Inventor. Jakarta: PT Elex Media Komputindo, 2017.

[7] Pongtiku and Arry, metode penelitian kualitatif saja. jayapura: Nulis Buku, 2016.

[8] I. Hermawan, METODOLOGI PENELITIAN PENDIDIKAN KUANTATIF , KUALATIF DAN MIXED METHODE. Kuningan: Hidayatul Quran, 2019.

[9] S. Mulyani, Metode Analisis dan Perancangan Sistem. Bandung: Abdi Sismatika, 2016.

[10] R. Habibi, F. B. Putra, and I. F. Putri, Aplikasi Kehahadiran Dosen Menggunakan OOP PHP. Bandung: Kreatif Industri Nusantara, 2020. 